\title{
Effect of Oxygen-Reducing Atmospheres on the Safety of Packaged Shelled Brazil Nuts during Storage
}

\author{
Vildes Maria Scussel, Barbara Nantua Giordano, Vanessa Simao, Daniel Manfio, \\ Simone Galvao, and Manuel Nazaré Ferreira Rodrigues
}

Laboratory of Mycotoxicology and Food Contaminants, Department of Food Science and Technology, Center of Agricultural Sciences, Federal University of Santa Catarina, P.O. Box 476, Florianopolis, SC, Brazil

Correspondence should be addressed to Vildes Maria Scussel, vildescussel_2000@yahoo.co.uk

Received 31 January 2011; Revised 6 May 2011; Accepted 6 May 2011

Academic Editor: Charles L. Wilkins

Copyright (C 2011 Vildes Maria Scussel et al. This is an open access article distributed under the Creative Commons Attribution License, which permits unrestricted use, distribution, and reproduction in any medium, provided the original work is properly cited.

This work reports the application of oxygen- $\left(\mathrm{O}_{2}-\right)$ reducing atmosphere methods on stored shelled Brazil nut (Bertholletia excelsa H.B.K.) packs aiming to evaluate the degree of aflatoxin degradation, nuts lipid oxidative stability, fungi control, and hygienic conditions improvement. The methods applied were (a) ozone: $\mathrm{O}_{3}$, (b) carbon dioxide: $\mathrm{CO}_{2}$, and (c) $\mathrm{O}_{2}$ absorber pads with and without vacuum. From all modified atmospheres evaluated, the best performance was obtained with $\mathrm{O}_{3}$, either with or without vacuum. It was the only nut treatment that was able to degrade aflatoxins. None of the spiked (AFLs: $15 \mu \mathrm{g} \cdot \mathrm{kg}^{-1}$ ) nut samples $\mathrm{O}_{3}$ treated had aflatoxins detected up to the LC-MS/MS method LOQ $\left(0.36 \mu \mathrm{g} \cdot \mathrm{kg}^{-1}\right.$ for total AFLs), thus producing safer nuts. Also it kept the fatty acid oxidation indicator-malondialdehyde stable and improved the sensory attributes for consumer acceptance. In addition, the destruction of fungi and yeast was observed since the $\mathrm{O}_{3}$ application (from $1.8 \times 10^{4} \mathrm{cfu} / \mathrm{g}$ to $\mathrm{NG}=$ no growth). All other treatments stabilized and/or inhibited microorganisms' growth only. By adding $\mathrm{CO}_{2}$ gas also played an important role in the nut quality. Regarding cost, gaseous $\mathrm{O}_{3}$ showed to be of low cost for application in the nut packs.

\section{Introduction}

In nature, Brazil nuts (Bertholletia excelsa H.B.K.) that grow in the Amazon forest may get contaminated by fungi and aflatoxins [1-3], as other tree nuts. The aflatoxigenic Aspergillus species that have been isolated from Brazil nuts are A. flavus, A. parasiticus, and A. nomius [4-7]. Their growth is directly related to the climate conditions of that region and to the conditions during their storage, transport, and commercialization, if there is no control of moisture content (m.c.) and temperature. That can also occur if nuts are packaged in a microclimate rich in oxygen $\left(\mathrm{O}_{2}\right)$ and m.c. enough to allow microorganisms to grow $[1,8]$.

Studies have reported the use of modified atmospheres (MA) in food storage, extensive to packaging, to reduce $\mathrm{O}_{2}$ concentration by adding gases such as nitrogen, carbon dioxide $\left(\mathrm{CO}_{2}\right)$, and ozone $\left(\mathrm{O}_{3}\right)$ which lead to microorganisms (fungi, yeast, and bacteria) inhibition, maintenance of lipid stability, and reduction of grains/nuts/vegetable respiration [9-14]. Vacuum also is an alternative for $\mathrm{O}_{2}$ reduction and in recent years the addition of $\mathrm{O}_{2}$ absorber pads (which contains a mixture of iron salts) have been the newest alternative in packaged food [15-17]. Studies have reported $\mathrm{O}_{3}$ and $\mathrm{CO}_{2}$ effect on controlling microorganism growth in several agricultural commodities $[13,18-21] . \mathrm{CO}_{2}$ is a promising and efficient inactivating microorganisms' gas for application on nonthermal sterilization process [22, 23]. Maeba et al. (1988) reported the destruction and detoxification of $\mathrm{AFB}_{1}$ and $\mathrm{AFG}_{1}$ in agricultural products treated with $1.1 \mathrm{ppm}$ of $\mathrm{O}_{3}$ during 5 minutes [24]. Aflatoxin degradation in different food products, either fresh or processed at different $\mathrm{O}_{3}$ concentrations, has been reported by some authors [13, 25-28]. An advantage of gaseous $\mathrm{O}_{3}$, apart from being a powerful disinfectant, oxidant, and aflatoxins degrader, is that it decomposes quite fast into $\mathrm{O}_{2}$ and does not have toxic effect [29-31]. 


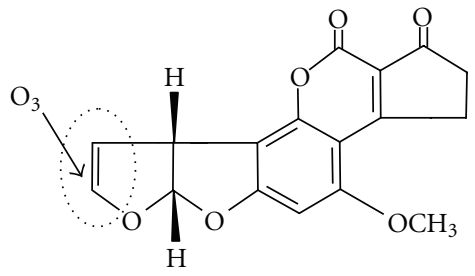

(a)

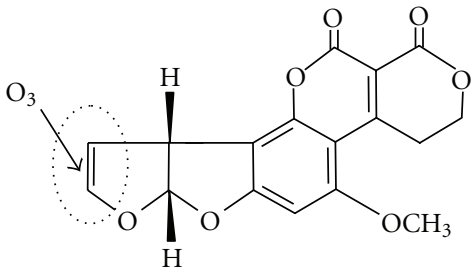

(b)

Figure 1: Chemical structures of the two more toxic aflatoxins, (a) $\mathrm{AFB}_{1}$ and (b) $\mathrm{AFG}_{1}$, with the sites of ozone oxidative attack (8,9 double bond of final furan rings in both structures).

The degradation of mycotoxins by $\mathrm{O}_{3}$ is found to follow a pseudo-first-order rate, as long as a continuous supply of $\mathrm{O}_{3}$ is maintained [8]. For aflatoxins, the higher degradation rate for $\mathrm{AFB}_{1}$ and $A F G_{1}$ was attributed to the presence of an 8,9 double bond forming a vinyl ether at the terminal furan ring (Figure 1), which is not present in $\mathrm{AFB}_{2}$ and $\mathrm{AFG}_{2}$. These latter forms require longer exposure due to a possible second mechanism, when the lactone ring is opened during $\mathrm{O}_{3}$ exposure [29].

High m.c., relative humidity, temperature, and environment rich in $\mathrm{O}_{2}$ are the main factors for tree nuts to get aflatoxin contaminated and so infected by fungi. During storage and commercialization dry shelled Brazil nut packs need to maintain their safety and quality. Considering that MA in storage (macroenvironment) and packaging (microenvironment) can prolong food shelf life by reducing $\mathrm{O}_{2}$ concentration, this work reports the application of $\mathrm{O}_{2}$ reducing atmosphere methods (vacuum, $\mathrm{CO}_{2}, \mathrm{O}_{3}$, and $\mathrm{O}_{2}$ absorber) on fungi reduction, aflatoxin degradation, and lipid stability during storage of snack packs of shelled Brazil nuts.

\section{Material and Methods}

2.1. Sample. Shelled dry (processed) Brazil nuts $(25 \mathrm{~kg})$. They were provided by the Renmero Factory from Cameta city, Para State, Northern Brazil. The nuts type and conditions were as follows: (a) medium size $(40-50 \mathrm{~mm}$ length [32]); (b) initial m.c. and total fungi load of $6.5 \%$ and $1.83 \times 10^{4} \mathrm{cfu} \cdot \mathrm{g}^{-1}$, respectively; (c) no aflatoxin contaminated (method LOQ: $0.36 \mu \mathrm{g} \cdot \mathrm{kg}^{-1}$ ); (d) absence of coliforms, Salmonella and Staphylococcus. That batch was utilized for the aflatoxin spiking experiment. A special nut batch $(10 \mathrm{~kg})$ naturally aflatoxin contaminated $\left(10.61 \mu \mathrm{g} \cdot \mathrm{kg}^{-1}\right)$ was used for further aflatoxin $\mathrm{O}_{3}$ degradation comparison. Its m.c. and total fungi load were $7.2 \%$ and $3.7 \times 10^{4} \mathrm{cfu} \cdot \mathrm{g}^{-1}$, respectively. Nuts $260 \mathrm{~g}$ portions were prepared for the experiments.

2.2. Application of $\mathrm{O}_{2}$-Reducing Atmospheres. Shelled Brazil nuts were divided into two groups. (a) Group I: control: nuts packed (a.1) loose: only air inside and (a.2) under vacuum. (b) Group II: aflatoxin spiked $\left(15 \mu \mathrm{g} \cdot \mathrm{kg}^{-1}\right)$ : nuts were divided into subgroups and packed (b.1) loose: only air inside; (b.2) vacuum; (b.3) $\mathrm{O}_{3}$ treated (packed with and without vacuum); (b.4) $\mathrm{CO}_{2}$ gas added into packs; (b.5) $\mathrm{O}_{2}$ absorber pads (packed with and without vacuum). The series
$\mathrm{O}_{3}$ (concentration: $10.0 \mathrm{mg} / \mathrm{L}, 90 \mathrm{~min}-[21]$ ) was applied on the nuts separately and then aseptically packaged. The $\mathrm{O}_{3}$ concentration checking was performed by the iodine metric test [33]. (c) Group II: naturally aflatoxin contaminated $\left(10.6 \mu \mathrm{g} \cdot \mathrm{kg}^{-1}\right)$ : nuts $\mathrm{O}_{3}$ treated were packed with and without vacuum. The $\mathrm{O}_{3}, \mathrm{CO}_{2}$ gas, and $\mathrm{O}_{2}$ absorber pad application was carried out utilizing an $\mathrm{O}_{3}$ generator ( $\mathrm{MZ01}$, MegaZon, Pondicherry, India), a $\mathrm{CO}_{2}$ cilinder (White Martins, Jundiaí, SP, Brazil), and $\mathrm{O}_{2}$ pad (Ageless, New York, USA), followed by sealing and/or vacuum + sealing by means of a vacuum machine with heat sealer (Sunnyvale, CA, USA). The snack packs $\left(\mathrm{O}_{2}\right.$ and UV barrier polypropylene film, $20 \times 25 \mathrm{~cm}$ length $\times$ width) filled with $260 \mathrm{~g}$ nut portions each and treated, were stored in an BOD incubator (Dist, Florianopolis, SC, Brazil.) at $27^{\circ} \mathrm{C}$ during two months.

Sample Collection for Analysis. Individual packs of shelled Brazil nuts were collected at Day one (after each treatment) and every 30 days (triplicate $n=3$ ). See flowchart of the whole experiment in Figure 2.

2.3. Shelled Brazil Nut Analysis. (a) Microbiological methods: for total fungi count the method was of Pitt and Hocking (1997) [33]; the presence of Aspergillus species was checked utilizing the Aspergillus flavus and parasiticus agar (Fluka, St. Gallen, Switzerland) by Pitt et al. (1983) [34]; the identification of fungi in genus and species was carried out according to the keys of Samsom et al. (2004) [35] and Salmonella spp., Staphylococcus spp., and coliforms $\left(45^{\circ} \mathrm{C}\right)$ were checked by APHA (1997) [36]. (b) Aflatoxin determination: was carried out by LC tandem mass spectrometry [37]. Briefly, aflatoxins (Sigma, Zwijndrecht, The Netherlands) were extracted from ground Brazil nuts with acetonitrile: water (HPLC grade, Carlo Erba, Milan, Italy and MilliQ, Millipore, Bedford, MA, USA, resp.) at $80: 20 \mathrm{v} / \mathrm{v}$, mixed, filtered, and injected into an Waters Alliance 2695 separation module with a $20 \mu \mathrm{L}$ injection loop (Waters, Milford, USA) and a $\mathrm{C}_{18}$ column $150 \times 3.2 \mathrm{~mm}, 5 \mu \mathrm{m}$ (Alltech, Breda, The Netherlands) at $30^{\circ} \mathrm{C}$. Separation was performed utilizing methanol (Carlo Erba) : water (both with $25 \mathrm{mM}$ of ammonium acetate, J. T. Baker, Phillipsburg, NJ, USA) as mobile phase at $1 \mathrm{~mL} \cdot \mathrm{min}^{-1}$ of flow rate. The LC system was coupled to a Quatro Ultima triple quadrupole mass spectrometer (Micromass, Manchester, UK) and toxins were detected and quantified by using atmospheric pressure chemical ionization in the positive 


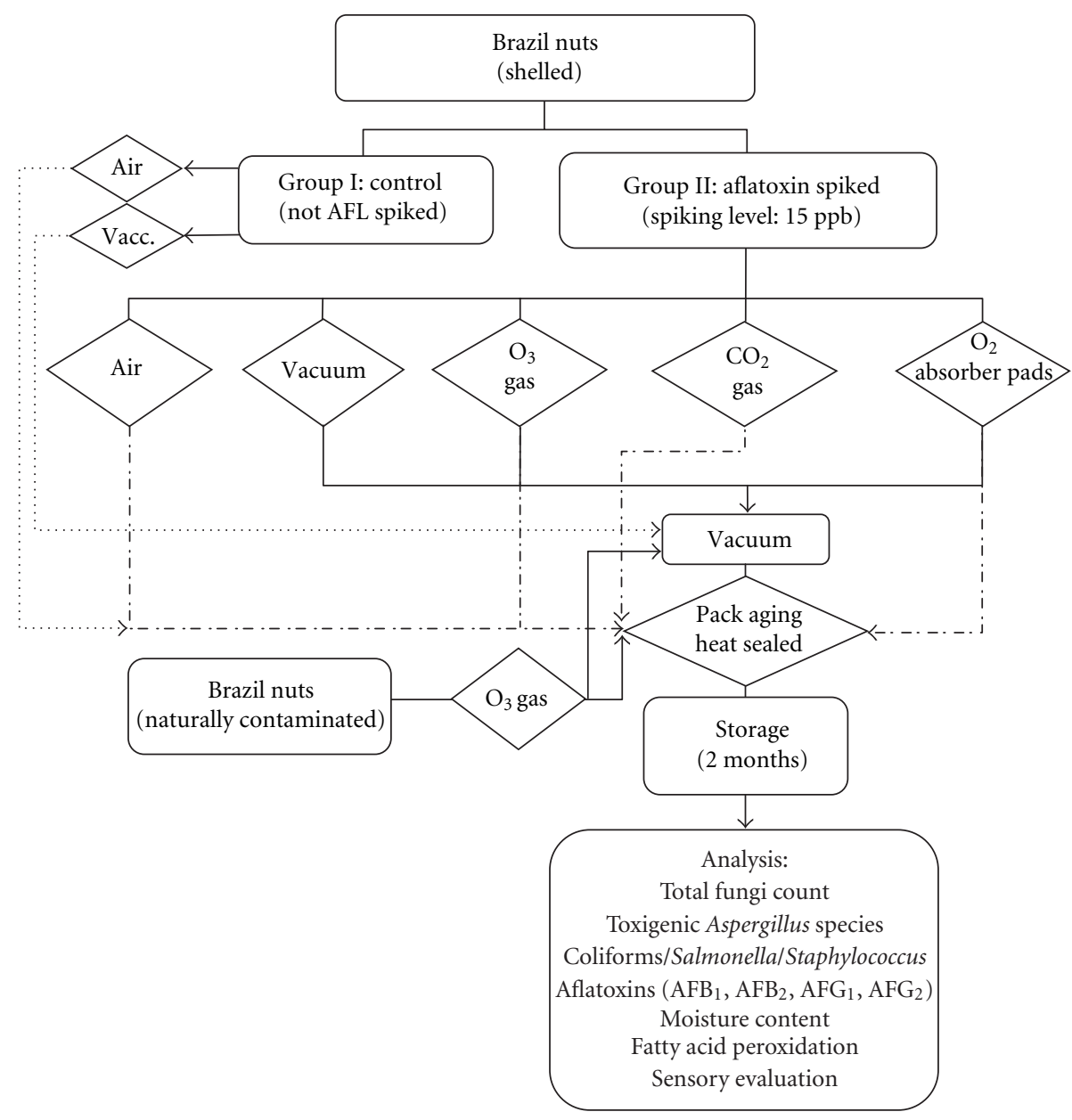

FIGURE 2: Chart flow of the oxygen-reducing atmospheres application on shelled Brazil nuts packs during storage.

mode $[\mathrm{M}+\mathrm{H}]^{+}$. For details on equipment settings, please refer to the method. (c) Moisture content was determined by gravimetry [38]. (d) Fatty acid oxidation was determined by the TBA method of Genot (1996). Extraction with 5\% TCA (J. T. Baker) containing freshly prepared BHT in ethanol (J. T. Baker and Carlo Erba, resp.). After filtration, extract was mixed with TBA (J. T. Baker,) and immersed in a $70^{\circ} \mathrm{C}$ water bath (Dubnoff Q226D, Quimis, Diadema, Brazil) for $30 \mathrm{~min}$, cooled in ice and the absorbance of the reacted solutions read at $532 \mathrm{~nm}$ (spectrophotometer E005, Hitashi, Tokyo, Japan) against a blank containing TCA and TBA reagents. The results expressed as $\mathrm{mg}$ of malondialdehyde (MDA) equivalents per kilograms nut sample (LOQ: $0.37 \mathrm{mg} \cdot \mathrm{kg}^{-1}$ ) [39]. (e) Sensory evaluation was based on the descriptive quantitative analysis [40]. Eighteen trained panelists during four sessions $(n=4)$ described impressions perceived by the hedonic scale of 5 points (1: dislike very much, 2: dislike, 3: neither like nor dislike, 4: like and 5: like very much). Sensory attributes evaluated: nut appearance (AP), color (CO), firmness (FI), resistance to slicing (SR), rancid (RA), and strange $(\mathrm{OD})$ odors.

2.4. Statistical Analysis. The results were expressed as the mean values and standard errors. Statistical analysis was performed by analysis of variance (ANOVA) and included the Tukey's test to evaluate significant differences among the means $(P<0.05)$. Figure 2 shows the flowchart on the whole study.

\section{Results and Discussion}

All the MA-treated shelled Brazil nut packs presented better quality and safety than the MA-untreated nuts (Group I: air) throughout the whole storage period. It was observed different degrees of fungi reduction and in some groups, aflatoxin degradation too. Table 1 shows the safety (fungi load; aflatoxins) and quality (m.c.; fatty acid oxidation; sensory evaluation) data obtained from the different MA-treated nut Groups (I, II, and III).

3.1. MA Effects on Shelled Brazil Nuts Microbiological Content and M.C. As expected, inhibition of microoganisms growth was registered throughout the experiment despite the MA applied.

(a) Total Fungi Load and Aflatoxigenic Strains. A substantial fungi reduction was observed, both with $\mathrm{O}_{2}$ absorber and 
International Journal of Analytical Chemistry

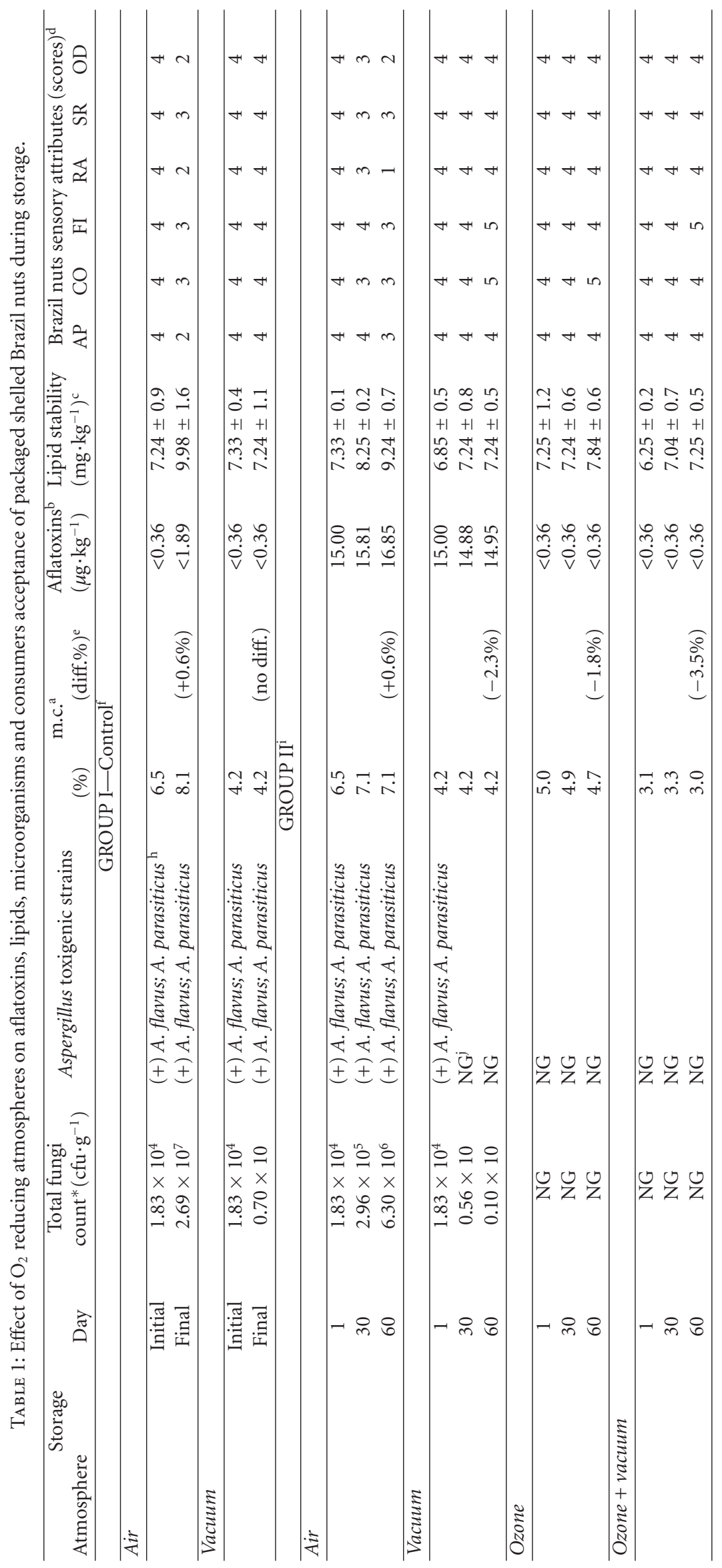




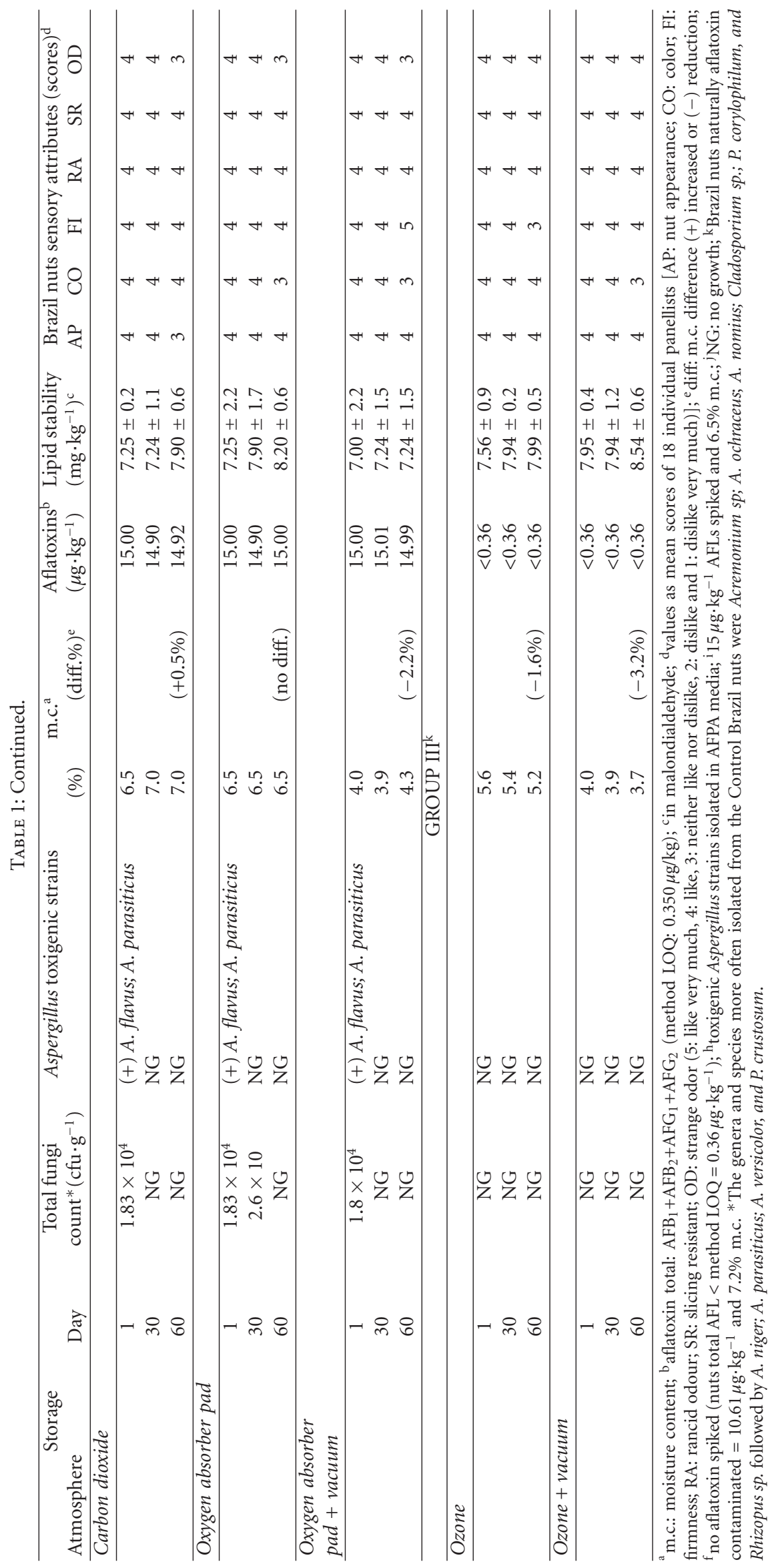


$\mathrm{O}_{3}$ packaged under vacuum, as well as with nuts $\mathrm{O}_{3}$ loose pack ones. $\mathrm{CO}_{2}$ also played an important role in the microorganism reduction in the current experiment reducing from $1.8 \times 10^{4} \mathrm{cfu} \cdot \mathrm{g}^{-1}$ to $\mathrm{NG}$ (no grow). Applying vacuum improved quality and safety regarding fungi further. Although, it was observed a reduction on their growth in the MA-treated Groups; in the untreated nuts (Group I) was possible to isolate and identify them. Their main genera and species were Acremonium sp; A. ochraceus; Cladosporium sp.; P. corylophilum Rhizopus sp. followed by A niger; A. parasiticus; A. versicolor; P. crustosum. With regards to m.c., nuts presented different degree of reduction after being MAtreated as follows: $\mathrm{O}_{3}+\mathrm{vac}>\mathrm{vac}>\mathrm{O}_{2}$ abs $+\mathrm{vac}>\mathrm{O}_{3}>\mathrm{CO}_{2}$. That was especially true for vacuum treated packs, which led to a synergistic effect (low m.c. + lack of $\mathrm{O}_{2}$ ) on controlling fungi growth. Regarding the $\mathrm{O}_{3}$ treated nuts, the reduction of m.c. was due to the fact that during $\mathrm{O}_{3}$ application occurred an exposure of nuts to 90 minutes with $\mathrm{O}_{3}$ stream that can take moist from nut surface apart from its known reaction with atmospheric water, decreasing the microenvironment relative humidity [21]. In fact, the lowest total fungi count, that is, no growth was detected in the packs that nuts were submitted to $\mathrm{O}_{3}$ with or without vacuum application (m.c. reduction: -1.8 and $-3.5 \%$, resp.), suggesting that apart from the fungi destruction by the $\mathrm{O}_{3}$, the reduction of m.c. powered fungi reduction. These data were corroborated by some authors that reported m.c. reduction in different foods including in-shell Brazil nuts $\mathrm{O}_{3}$ treated $[1-3,21]$.

(b) Hygienic Bacterial Indicators. Similar to what was observed for fungi and yeast, all gases and $\mathrm{O}_{2}$ absorbers as well as vacuum did not allow Salmonella, Staphylococcus, or coliform to grow on the nuts showing the safe power of the treatments for microbial population control. It is important to emphasize that the potent disinfectant characteristics of $\mathrm{O}_{3}$ has been recognized by the Food and Agriculture Organization [41] and Food and Drug Administration [42].

3.2. MA Effects on Shelled Brazil Nuts Aflatoxin Degradation. It was possible to observe in the aflatoxin spiked nut samples $\mathrm{O}_{3}$ treated (Groups II: $\mathrm{O}_{3}$ and $\mathrm{O}_{3}+\mathrm{vac}$ ) that the gas was able to degrade them as none, during the storage period, were detected (LC-MS/MS method LOQ: $0.36 \mu \mathrm{g} \cdot \mathrm{kg}^{-1}$ ). That was different for the other $\mathrm{O}_{2}$ reducing atmospheres $\left(\mathrm{CO}_{2}\right.$ and $\mathrm{O}_{2}$ absorber pads with/without vacuum). They were able only to stabilize/reduce the microorganisms growth keeping nuts safe but with aflatoxins. In that sense the packs with $\mathrm{O}_{3}$ and vacuum applied bring an alternative for aflatoxin degradation and also m.c. reduction, a factor that is directly related to fungi proliferation and development of possible aflatoxigenic strains. Nuts $\mathrm{O}_{3}$ treated utilized in the study showed to be able for consumption, as no aflatoxin was detected in none of them. Brazil nuts naturally contaminated by $\mathrm{O}_{3}$ : to make sure $\mathrm{O}_{3}$ would degrade aflatoxins not only in spiked nuts (i.e., toxins just applied and dried onto nut surfaces), we carried out also an experiment utilizing the special batch of nuts naturally aflatoxin-contaminated (packs with nuts $\mathrm{O}_{3}$ and $\mathrm{O}_{3}+$ vacuum treated). Similarly to the nuts spiked, no aflatoxin was detected after $\mathrm{O}_{3}$ application neither fungi. That was probably due to the fact that Brazil nut has the advantage of its contamination/fungi proliferation to occur mostly on the nut surface/external layer as its structure is completely sealed (Figure 3 ). In addition, the testae (a pellicle that surrounds the edible part) of the Brazil nut, which is rich in Selenium (antioxidant), can act as a protector [2]. Thus reducing the possibility of easy access by the fungi spores to the nut core, as it occurs in peanuts (loose testae) or shelter fungi spores in-between shell and edible part of pistachios (in-shell), making gaseous $\mathrm{O}_{3}$ application and action more effective. Currently, there is no available technology to completely eliminate the mycotoxin contamination of food and feed chain. Most of the current strategies for mycotoxin reduction are based on prevention, either pre- or postharvest and detoxification, which are not always effective. From the available tools to ensure food safety, $\mathrm{O}_{3}$ application may be one of the most promising methods that come to meet the grain producers and food industries needs [43-45].

\section{3. $\mathrm{O}_{2}$-Reducing Atmosphere Effect on Nuts Quality. As far} as quality is concerned, the parameters evaluated were the fatty acid oxidation, m.c., and sensorial evaluation which give information on lipid rancidity development, crunchiness texture alterations, and aroma/colour/odor/texture modifications. (a) Fatty acid peroxidation: regarding MDA formation during the nuts storage period and MA applied, no significant changes occurred despite the MA applied except for the $\mathrm{O}_{2}$ absorber at the end of the storage period. In contrary, the samples packed loose in air (either Control and spiked) had an increase of MDA from 7.24 to $9.98 \mathrm{mg} \cdot \mathrm{kg}^{-1}$. With regards to $\mathrm{CO}_{2}$ and $\mathrm{O}_{3}$, with and without vacuum, effect on shelled Brazil nuts lipids, it was observed that the values of MDA lowered and kept constant throughout the whole period of storage (Table 1). The same occurred when Gamli and Hayoğlu (2007) studied vacuum packaged pistachio [46]. The authors observed no significant difference on the MDA values during the storage period and reported that those results could be attributed to the higher amount of the fatty acid oleic acid (monounsaturated) and less linoleic acid (poliunsaturated) content in that nut. These results can be attributed to the reduction/control in the oxidation rate speed, both, by air withdraw (vacuum) and $\mathrm{O}_{3}$ treatment (waste from $\mathrm{O}_{2}$ removal). Similar results occurred in peppers and pistachio after the application of $\mathrm{O}_{3}$ and vacuum packaging, that is, the effect on lipid oxidation was not apparent, thus could not alter the sensory characteristics [13] which was corroborated with the current data of the Brazil nut experiment. It is different when Rudolph et al. (1992) evaluated the oxidative stability of pecan oil and observed that changes in colour $\left(\mathrm{O}_{2}\right.$ effect on carotenoids) followed by a rapid increase of rancidity products $\left(\mathrm{O}_{2}\right.$ effect on fatty acids) [47]. However in the case of oil, lipids (fatty acids) present much more intense exposure to air $\mathrm{O}_{2}$ than when it is protected in the liposomes inside the nut cells (or just the nut damaged surface exposes their lipid content from broken cells/lysosomes. As for Brazil nuts 


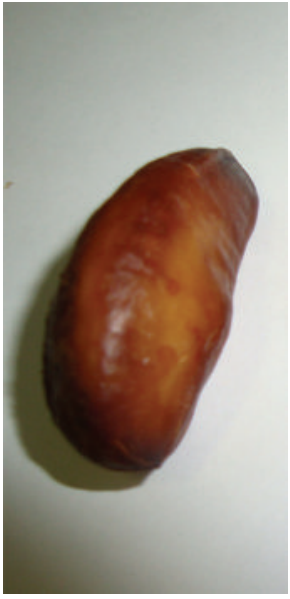

(a)

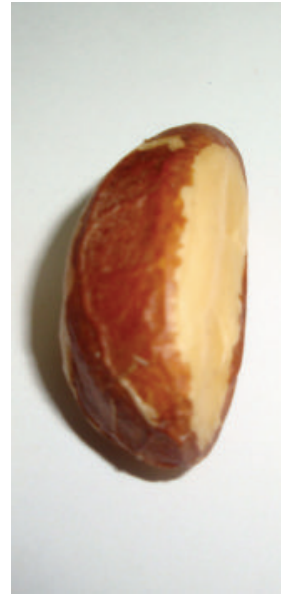

(b)

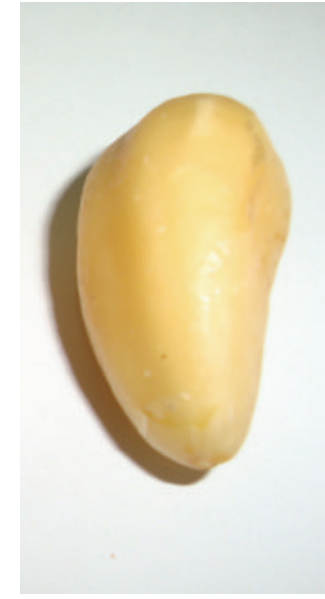

(c)

FIGURE 3: Shelled dry Brazil nuts (a) totally protected by the testae, (b) with some remained testae, and (c) totally cleaned for packaging, showing its sealed nut surface.

where their oil (lipids) is protected inside the undamaged nut cells or slightly damaged during the industrial nut cracking procedure. (b) Sensory Evaluation: the scores for the sensory attributes tested (nut appearance, strange odor, rancid odor, slicing resistance, and firmness) are shown in Table 1. The $\mathrm{O}_{2}$ absorber pads applied led to some slight variation with regards to the visual appearance (color) of nuts probably due to its reducing effectiveness in the nuts located away from the pad site, sitting for long time (60 days) during storage. The sensory analysis of the Brazil nuts treated with $\mathrm{O}_{3}$ and vacuum-packed did not present significant changes among the panelists $(P<0.05)$. All scores for the $\mathrm{O}_{3}$-treated nuts during storage period were between 4 (like) and 5 (like very much). It was verified also that $\mathrm{O}_{3}$ leaves no residual odor. In fact $\mathrm{O}_{3}$ with vacuum and vacuum only received the best scores showing that vacuum is still the best choice when preserving sensory characteristics is concerned. Similar thing occurred when Inan et al. (2006) worked with red pepper ozonation [27]. They did not register significant sensory changes after the $\mathrm{O}_{3}$ application as the peppers were still quite palatable. When Akbas and Ozdemir (2006) studied the quality of pistachio, no significant changes also were observed between sweetness, rancidity, overall appearance, and taste, compared to control samples $\left(\right.$ no $\left.\mathrm{O}_{3}\right)$ indicating the efficacy of that gas application [13]. Other authors also have reported the efficiency of the $\mathrm{O}_{3}$ and its low interference in the sensory attributes of quality in several products such as vegetables, fish, birds carcasses, and their byproducts $[44,48,49]$. In a work carried by Dull and Kays (1988) with pecans, the author reported a slight better sensory quality on the vacuum-treated packaging nuts after 6 months of storage at $24^{\circ} \mathrm{C}$. Other potential uses of $\mathrm{O}_{3}$ in the food industry include reduction of undesirable volatile metabolites, such as off-flavours or contaminants by their removal during $\mathrm{O}_{3}$ stream application [50]. Considering that MDA is volatile, all experiments that had vacuum applied and/or gaseous $\mathrm{O}_{3}$ stream exposure, had lower MDA just after application (day one), thus giving the idea of fast oxidation reduction which was expected. The nuts final storage MDA measure should be taken as the indicator of the degree of oxidation together with the sensory evaluation. (c) Moisture content: as expected, nuts presented m.c. reduction after the MA treatments. That was especially true for vacuum-treated packs which kept nuts cruncher throughout the whole storage period. That effect was enhanced by the $\mathrm{O}_{3}$ application which allowed to reduce possible off-odours.

\section{General Discussion}

All $\mathrm{O}_{2}$-reducing atmospheres treated Brazil nut packs presented better nut quality after the period of study. However, the best performance, regarding safety was obtained either with or without vacuum. It was the only nut treatment that was able to degrade aflatoxins. It also led to fungi/yeast destruction, was able to eliminated off-flavours, reduced m.c., and maintained fatty acid oxidative process stable thus leading to safer, cruncher, and of better quality nuts. Next comes vacuum that kept sensory attributes of consumer acceptance, kept controlled lipid oxidation, and microorganisms. All other treatments stabilized and/or inhibited microorganisms' growth only, which also is important regarding safety, microorganisms-wise, and quality nuts.

Considering that Brazil nuts can be suitable to aflatoxin contamination, are good fungi substrate, and are rich in oil, as other tree nuts, the best method that could control those parameters and improve consumer acceptance for best and stable dry nut product packs is $\mathrm{O}_{3}$ with vacuum. Aflatoxin that may still remain in the Brazil nuts at the packaging can be destroyed at that stage. $\mathrm{O}_{3}$ will be useful for those hard packages (tubs) sold in small portion, that are commonly commercialized in Brazil too-providing a safer product for the national consumers. Regarding the costs and environment impact, $\mathrm{O}_{3}$ equipments are of low cost and environment friendly, it is fast converted into $\mathrm{O}_{2}$.

Our modern days have been emphasizing the importance of additives reduction in food. The use of $\mathrm{O}_{3}$ features as 
an important technology for food storage and industry as it leaves no residue. Its use has been approved in countries around the world and supported by several international food and health agencies inclusive for use in organically labelled agricultural products, inclusive in medicine. Currently, there is no available technology to completely eliminate the mycotoxins contamination of food and feed chain. Most of the current strategies for mycotoxin reduction are based on prevention, either pre- or postharvest. From the available tools to ensure food safety, $\mathrm{O}_{3}$ application is one of the most promising methods that come to meet the needs.

\section{Acknowledgments}

The authors thank the Renmero Factory and the Brazilian Association of Brazil Nuts Producers located in Cameta, Para State, in the Eastern Brazilian Amazon Region for providing the shelled dry Brazil nut samples.

\section{References}

[1] S. J. Kershaw, "Aflatoxins in imported edible nuts: some data 1982-1984," Journal of Food Technology, vol. 20, no. 5, pp. 647649, 1985.

[2] A. M. Pacheco and V. M. Scussel, "Selenium and aflatoxin levels in raw Brazil nuts from the amazon basin," Journal of Agricultural \& Food Chemistry, vol. 55, no. 26, pp. 1108711092, 2007.

[3] A. M. Pacheco and V. M. Scussel, "Aflatoxins evaluation on in-shell and shelled dry brazil nuts for export analysed by LCMS/MS-2 006 \& 2007 harvests," World Mycotoxin Journal, vol. 2, no. 3, pp. 295-304, 2009.

[4] C. Cartaxo, J. Souza, T. Correa, P. Costa, and O. Freitas-Costa, "Occurrence of aflatoxins and filamentous fungi contamination in Brazil nuts in the forest," in IVth Congresso LatinoAmericano de Micotoxicologia, Havana, Cuba, September 2003.

[5] K. Arrus, G. Blank, D. Abramson, R. Clear, and R. A. Holley, "Aflatoxin production by Aspergillus flavus in Brazil nuts," Journal of Stored Products Research, vol. 41, no. 5, pp. 513-527, 2005.

[6] V. M. Scussel, "Aflatoxin and food safety: recent south American perspectives," Journal of Toxicology, Section Toxin Review, vol. 23, no. 2-3, pp. 179-216, 2004.

[7] M. Olsen, P. Johsson, T. Moller, R. Paladino, and M. Lindblat, "Aspergillus nomius, an important aflatoxin producer in Brazil nuts?" World Mycotoxin Journal, vol. 1, pp. 123-126, 2008.

[8] K. S. McKenzie, A. B. Sarr, K. Mayura et al., "Oxidative degradation and detoxification of mycotoxins using a novel source of ozone," Food and Chemical Toxicology, vol. 35, no. 8, pp. 807-820, 1997.

[9] J. Zhao and P. M. Cranston, "Microbial decontamination of black pepper by ozone and the effect of the treatment on volatile oil constituents of the spice," Journal of the Science of Food and Agriculture, vol. 68, no. 1, pp. 11-18, 1995.

[10] J. G. Kim and A. E. Yousef, "Inactivation kinetics of foodborne spoilage and pathogenic bacteria by ozone," Journal of Food Science, vol. 65, no. 3, pp. 521-528, 2000.

[11] M. Achen and A. E. Yousef, "Efficacy of ozone against Escherichia coli O157:H7 on apples," Journal of Food Science, vol. 66, no. 9, pp. 1380-1384, 2001.
[12] R. R. Sharma, A. Demirci, L. R. Beuchat, and W. F. Fett, "Inactivation of Escherichia coli O157:H7 on inoculated alfalfa seeds with ozonated water and heat treatment," Journal of Food Protection, vol. 65, no. 3, pp. 447-451, 2002.

[13] M. Y. Akbas and M. Ozdemir, "Effect of different ozone treatments on aflatoxin degradation and physicochemical properties of pistachios," Journal of the Science of Food and Agriculture, vol. 86, no. 13, pp. 2099-2104, 2006.

[14] H. Ölmez and M. Y. Akbas, "Optimization of ozone treatment of fresh-cut green leaf lettuce," Journal of Food Engineering, vol. 90, no. 4, pp. 487-494, 2009.

[15] S. F. Mexis, A. V. Badeka, K. A. Riganakos, and M. G. Kontominas, "Effect of active and modified atmosphere packaging on quality retention of dark chocolate with hazelnuts," Innovative Food Science and Emerging Technologies, vol. 11, no. 1, pp. 177186, 2010.

[16] Freshpax, 2011, http://www.multisorb.com/products/freshpax .html.

[17] Ageless, 2011, http://www.idspackaging.com/packaging/us/ Products_category.html.

[18] F. M. Gabler, J. L. Smilanick, M. F. Mansour, and H. Karaca, "Influence of fumigation with high concentrations of ozone gas on postharvest gray mold and fungicide residues on table grapes," Postharvest Biology and Technology, vol. 55, no. 2, pp. 85-90, 2010.

[19] M. Maskan and Ş. Karataş, "Storage stability of whole-split pistachio nuts (Pistachia vera L.) at various conditions," Food Chemistry, vol. 66, no. 2, pp. 227-233, 1999.

[20] G. Mazza and D. S. Jayas, "Controlled and modified atmosphere storage," in Food Shelf Life Stability. Chemical, Biochemical and Microbiological Changes, N. A. M. Eskin and D. S. Robinson, Eds., CRC Press LLC, Boca Raton, Fla, USA, 2001.

[21] B. N. E. Giordano, V. Simão, and V. M. Scussel, "Effect of ozone gas on Brazil Nut (Bertholletia excelsa H.B.K.) mycoflora and aflatoxin reduction," in Proceedings of the 8th International Conference on Controlled Atmosphere and Fumigation in Stored Products (CAF'08), pp. 214-220, Chengdu, China, 2008.

[22] N. Kaliyan, R. V. Morey, W. F. Wilcke, K. Alagusundaram, and P. Gayathri, "Applications of carbon dioxide in food and processing industries: current status and future thrusts," in ASAE Annual Meeting 076113, http://www.asabe.org/.

[23] C. van der Steen, F. Devlieghere, and J. Debevere, "High oxygen concentration in combination with elevated carbon dioxide to affect growth of fresh-cut produce micro organisms," ISHS Acta Horticulturae, vol. 599, pp. 141-147, 2003.

[24] H. Maeba, Y. Takamoto, M. Kamimura, and T. Miura, "Destruction and detoxification of aflatoxins with ozone," Journal of Food Science, vol. 53, pp. 667-668, 1988.

[25] F. G. Dollear, G. E. Mann, L. P. Codifer, H. K. Gardner, S. P. Koltun, and H. L. E. Vix, "Elimination of aflatoxins from peanut meal," Journal of the American Oil Chemists' Society, vol. 45, no. 12, pp. 862-865, 1968.

[26] A. D. Proctor, M. Ahmedna, J. V. Kumar, and I. Goktepe, "Degradation of aflatoxins in peanut kernels/flour by gaseous ozonation and mild heat treatment," Food Additives and Contaminants, vol. 21, no. 8, pp. 786-793, 2004.

[27] F. Inan, M. Pala, and I. Doymaz, "Use of ozone in detoxification of aflatoxin $B_{1}$ in red pepper," Journal of Stored Products Research, vol. 43, no. 4, pp. 425-429, 2007.

[28] B. N. E. Giordano and V. M. Scussel, "Effect of ozone gas on Brazil nut (Bertholletia excelsa H.B.K.) mycoflora and aflatoxin reduction during storage," Journal of Agriculture and Food Chemistry. In press. 
[29] U. Samarajeewa, A. C. Sen, M. D. Cohen, and C. I. Wei, "Detoxification of aflatoxins in foods and feeds by physical, chemical methods," Journal Food Protection, vol. 53, pp. 489 501, 1990.

[30] K. S. McKenzie, L. F. Kubena, A. J. Denvir et al., "Aftatoxicosis in Turkey poults is prevented by treatment of naturally contaminated corn with ozone generated by electrolysis," Poultry Science, vol. 77, no. 8, pp. 1094-1102, 1998.

[31] B. N. E. Giordano, V. Simao, D. Manfio, S. Galvao, J. N. Scussel, and V. M. Scussel, "Reduction of in-shell Brazil nut on aflatoxin contamination by ozone application during storage," in Proceedings of the 10th International Working Conferences on Stored-Product Protection (IWCSPP '10), M. O. Carvalho, P. G. Fields, C. S. Adler et al., Eds., Estoril, Portugal, 2010.

[32] F. R. De Mello and V. M. Scussel, "Characteristics of in-shell Brazil nuts and their relationship to aflatoxin contamination: criteria for sorting," Journal of Agricultural \& Food Chemistry, vol. 55, no. 22, pp. 9305-9310, 2007.

[33] J. I. Pitt and A. D. Hocking, Fungi \& Food Spoilage, Blackie Academic \& Profissional, London, UK, 2nd edition, 1997.

[34] J. I. Pitt, D. Hocking, and D. R. Glenn, "An improved medium for the detection of Aspergillus flavus and A. parasiticus," Journal of Applied Bacteriology, vol. 54, no. 1, pp. 109-114, 1983.

[35] R. A. Samsom, E. S. Hoesktra, and J. C. Frisvad, Introduction to Food and Airborne Fungi, CBS, Utrecht, The Netherlands, 7th edition, 2004.

[36] APHA-American Public Health Association, Compendium of Methods for the Microbiological Examination of Foods, 3rd edition, 1997.

[37] J. J. M. Xavier and V. M. Scussel, "Development of an LCMS/MS method for the determination of aflatoxins $B_{1}, B_{2}, G_{1}$, and $\mathrm{G}_{2}$ in Brazil nut," International Journal of Environmental Analytical Chemistry, vol. 88, no. 6, pp. 425-433, 2008.

[38] AOAC, Official Methods of Analysis International Nuts and Nuts Products, vol. II, chapter 40, 18th edition, 2005.

[39] C. Genot, "Some factors influencing TBA test," Report of dietox project (AIRIII-CT-92-1577), 1996.

[40] H. S. Stone and J. L. Sidel, Sensory Evaluation Practices, Academc Press, Orlando, Fla, USA, 1993.

[41] FAO. Corporate DOC depository, "Fresh water fish processing and equipment in small plants," 1994, http://www.fao.org/ docrep/003/t1768e/T1768E07.htm.

[42] FDA. Food and Drug Administration, "Direct food substances affirmed as generally recognized as safe," 2008, http://www .accessdata.fda.gov/scripts/cdrh/cfdocs/cfcfr/CFRSearch.cfm? $\mathrm{fr}=184.1563$.

[43] R. Shapira and N. Paster, "Control of mycotoxins in storage and techniques for their decontamination," in Mycotoxins in Food: Detection and Control, N. Magan and M. Olsen, Eds., pp. 190-223, Woodhead Publishing and CRC Press, Cambridge, UK, 2004.

[44] S. Naito and H. Takahara, "Ozone contribution in food industry in Japan," Ozone: Science \& Engineering, vol. 28, no. 6, pp. 425-429, 2006.

[45] A. Halász, R. Lásztity, T. Abonyi, and Á. Bata, "Decontamination of mycotoxin-containing food and feed by biodegradation," Food Reviews International, vol. 25, no. 4, pp. 284-298, 2009.

[46] Ö. F. Gamli and İ. Hayoğlu, "The effect of the different packaging and storage conditions on the quality of pistachio nut paste," Journal of Food Engineering, vol. 78, no. 2, pp. 443-448, 2007.
[47] C. J. Rudolph, G. V. Odell, H. A. Hinrichs, H. J. Thomson, and S. J. Kays, "Chemical changes in pecan oils during oxidation," Journal of Food Quality, vol. 15, no. 4, pp. 279-293, 1992.

[48] J. M. King and T. Walker, "Ozone: new weapon for fighting food hazards," Louisiana Agriculture Magazine, vol. 43, pp. 12 13, 2000.

[49] Ş. Ibanoğlu, "Influence of tempering with ozonated water on the selected properties of wheat flour," Journal of Food Engineering, vol. 48, no. 4, pp. 345-350, 2001.

[50] G. G. Dull and S. J. Kays, "Quality and mechanical stability of pecan kernels with different packaging protocols," Journal of Food Science, vol. 53, no. 2, pp. 565-567, 1988. 


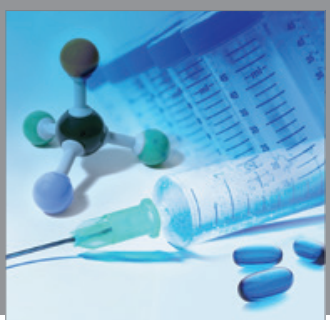

International Journal of

Medicinal Chemistry

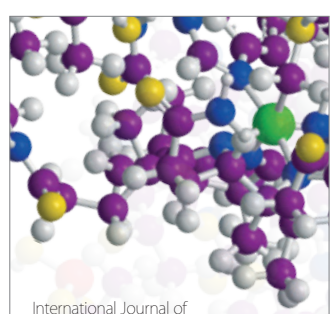

Carbohydrate Chemistry

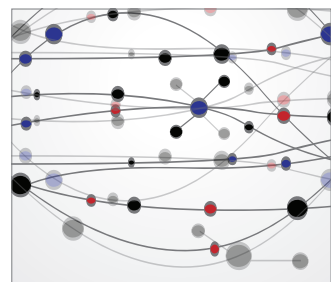

The Scientific World Journal
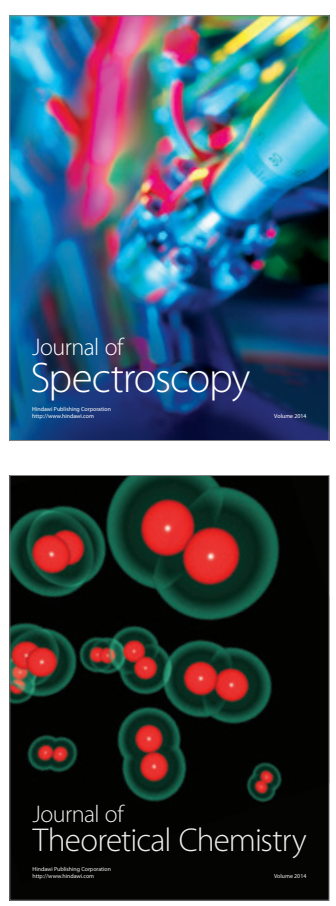
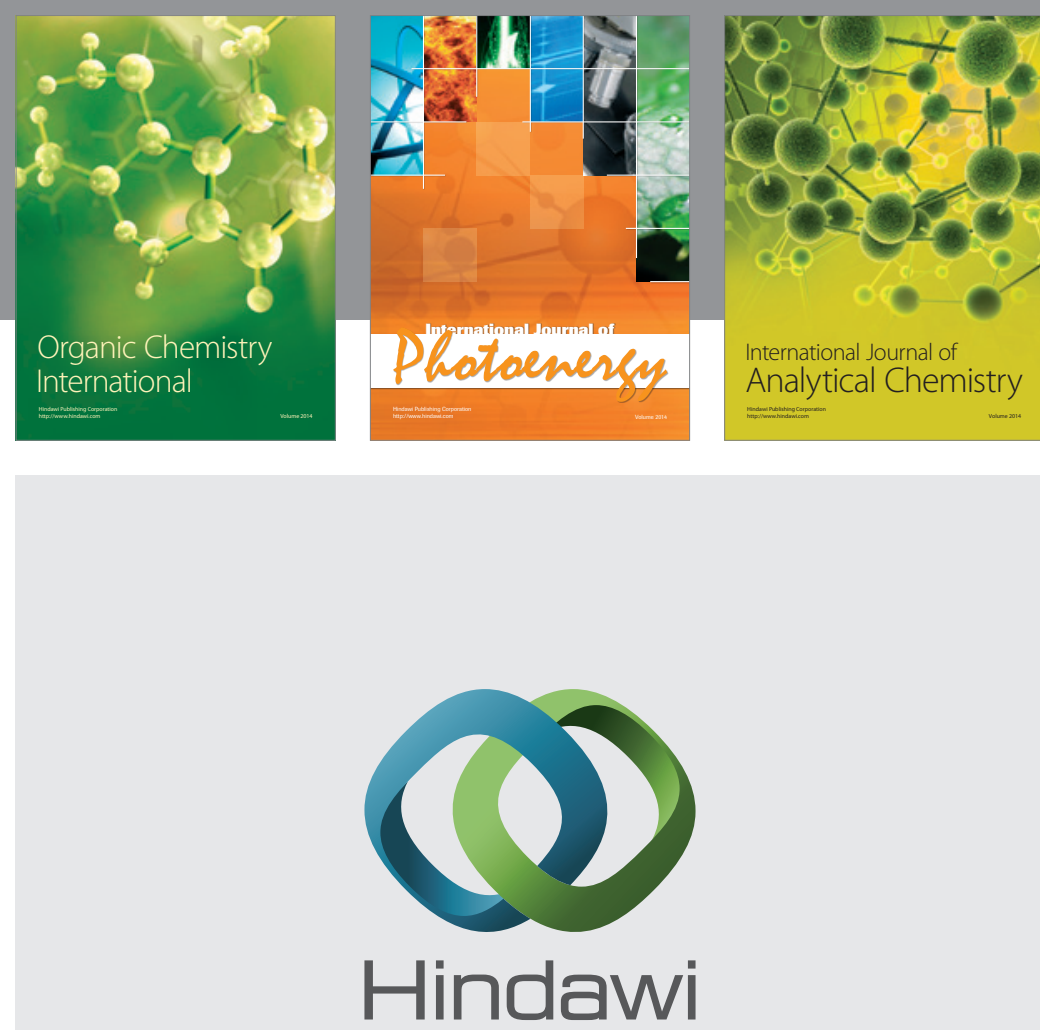

Submit your manuscripts at

http://www.hindawi.com
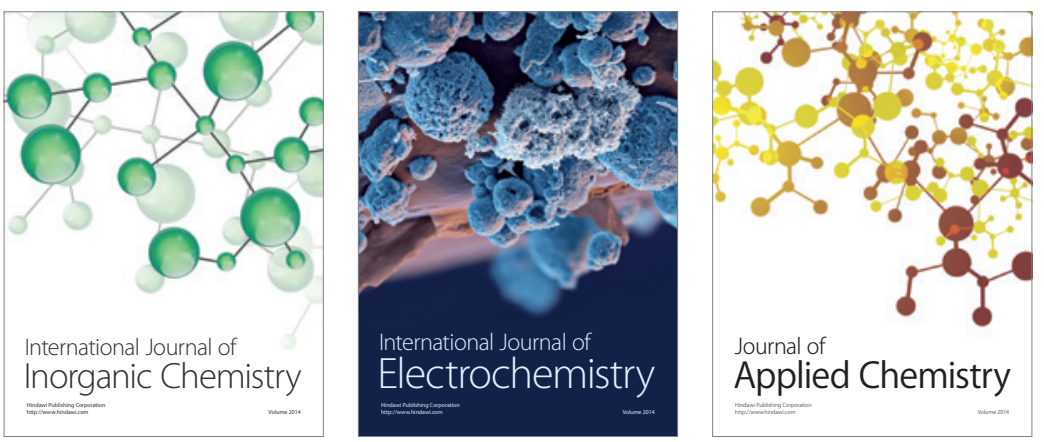

Journal of

Applied Chemistry
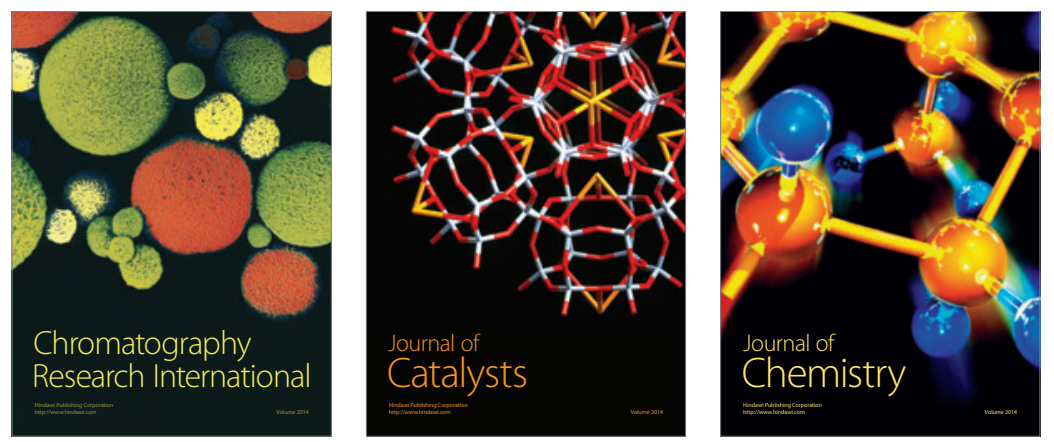
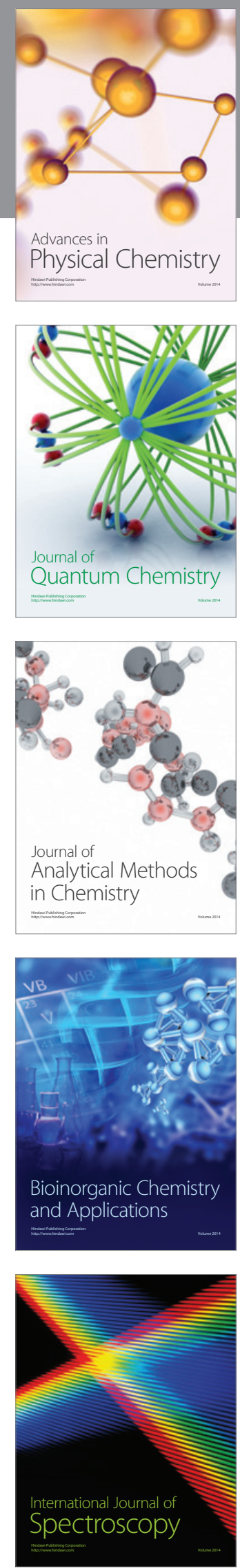